\title{
Metabolism and Pharmacokinetics of Rhynchophylline in Rats
}

\author{
Wei WAng, Chao-Mei MA, and Masao Hattori* \\ Division of Metabolic Engineering, Institute of Natural Medicine, University of Toyama; 2630 Sugitani, Toyama 930-0194, \\ Japan. Received November 4, 2009; accepted January 19, 2010; published online February 4, 2010
}

The alkaloid, rhynchophylline (RHY), from the stems and hooks of Uncaria rhynchophylla was revealed in recent years to have protective effect on neuronal damage. The present research was carried out to investigate the in vivo metabolism of this bioactive alkaloid. After administering RHY to rats, LC-MS detected RHY in plasma, bile, brain, urine and feces, the glucuronides, 11-hydroxyrhynchophylline 11- $O$ - $\beta$-D-glucuronide (M1) and 10hydroxyrhynchophylline 10-O- $\beta$-D-glucuronide (M2) in bile, and 11-hydroxyrhynchophylline (M3) and 10-hydroxyrhynchophylline (M4) in urine and feces. Within $24 \mathrm{~h}, 78.0 \%$ of RHY was excreted into the feces and $12.6 \%$ into the urine of rats after oral administration of $37.5 \mathrm{mg} / \mathrm{kg}$. Monitoring by LC-MS showed that $9.4 \%$ of RHY was metabolized to M3 and M4 in a ratio of about $1: 1$. RHY was also detected in the brain $(0.650 \mathrm{ng} / \mathrm{g})$ at $3 \mathrm{~h}$ after oral administration of the same dose. Cytochrome P450 (CYP) in rat liver microsomes played a key role in RHY hydroxylation. Specific inhibition of CYP isozymes indicated that CYP2D, CYP1A1/2 and CYP2C participated in RHY hydroxylation, but not CYP3A.

Key words alkaloid metabolism; pharmacokinetics; cytochrome P450; rhynchophylline; 10-hydroxyrhynchophylline; 11hydroxyrhynchophylline

Uncaria species are the key medicinal herbs in some important Kampo formulations, such as Chotosan and Yokukansan. The alkaloid constituents in Uncaria species are known to be the bioactive compounds. Extensive pharmacologic studies have been carried out on these bioactive alkaloids and interesting activities, such as beneficial effects on central nervous system were revealed. The tetracyclic oxindole alkaloid rhynchophylline (RHY) and its isomeric isorhynchophylline (ISOR) ${ }^{1)}$ are the major alkaloids of $U n$ caria species (Fig. 1). It has been reported that RHY and ISOR confer protective effects on ischemia-induced neuronal damage in the rat hippocampus, ${ }^{2)}$ suppressive effects on 5$\mathrm{HT}_{2 \mathrm{~A}}$ receptor function in the mouse brain ${ }^{3)}$ and vasodilator action. ${ }^{4)}$ Rhynchophylline also functionally turns delayed rectifiers into A-type $\mathrm{K}^{+}$channels. ${ }^{5)}$ Despite significant pharmacological effects, the metabolism and pharmacokinetics of RHY have not been reported, though the similar indole alka-

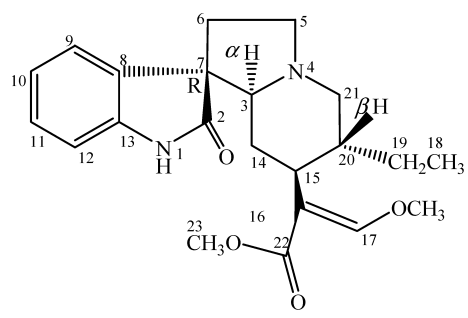

RHY

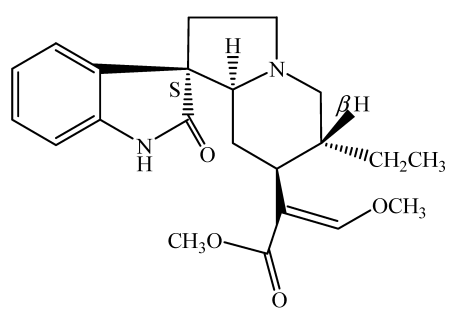

ISOR

Fig. 1. Structures of RHY and ISOR loid, yohimbine, was reported to be metabolized to 10-hydroxyyohimbine and 11-hydroxyyohimbine in humans. ${ }^{6}$ ) The biopharmaceutics of yohimbine and the pharmacokinetics of these metabolites in healthy men have also been described. ${ }^{7)}$ Here, we report the absorption, distribution, metabolism and excretion of RHY in rats monitored RHY and its in vivo metabolites by LC-MS.

\section{MATERIALS AND METHODS}

Apparatus Both ${ }^{1} \mathrm{H}-\mathrm{NMR}(400 \mathrm{MHz})$ and ${ }^{13} \mathrm{C}-\mathrm{NMR}$ $(100 \mathrm{MHz})$ spectra were recorded using a Jeol ECX-400P spectrometer with $\mathrm{CD}_{3} \mathrm{OD}$ as the solvent and tetramethylsilane (TMS) as the internal standard. Chemical shifts are shown as $\delta$ values in ppm downfield to TMS. Coupling constants $(J)$ are described in Hertz $(\mathrm{Hz})$. Singlet, doublet, triplet, multiplet and broad types of multiplicity are shown as $\mathrm{s}, \mathrm{d}, \mathrm{t}, \mathrm{m}$, and br, respectively. High-resolution fast atom bombardment mass spectrometry (HR-FAB-MS) proceeded using a Jeol JMS-AX505HAD mass spectrometer. Circular dichroic (CD) spectra $(c=0.2 \mathrm{mg} / \mathrm{ml}, \mathrm{MeOH}$, cell length of $1 \mathrm{~cm}$, volume of $2 \mathrm{ml}, 25^{\circ} \mathrm{C}$ ) were recorded on a Jasco J-805 spectropolarimeter. Optical rotation was measured using a Jasco DIP-140 digital polarimeter. Melting points were measured on a Yanaco micro melting point apparatus without correction.

Enzymes and Chemicals $\beta$-Glucuronidase (Type B-1), pooled microsomes from male rat liver (product number M9066), $\beta$-nicotinamide adenine dinucleotide 2 '-phosphate reduced tetrasodium salt hydrate $(\beta-\mathrm{NADPH})$, alamethicin, SKF-525A (SKF), quinine (QUI), $\alpha$-naphthoflavone (NAP), cimetidine (CIM), erythromycin (ERY), uridine 5'-diphosphoglucuronic acid trisodium salt (UDPGA) and other chemicals were purchased from Sigma (St. Louis, MO, U.S.A.). Elution solvents for LC-MS were of HPLC grade. We isolated RHY $(2.2 \mathrm{~g})$ from branch hooks of a mixture $(3 \mathrm{~kg})$ of Uncaria species including $U$. rhynchophylla Miquel, $U$. sinensis HAVILAND, and U. macrophylla WALLICH (Rubiaceae) (Tochimoto Tenkaido Co., Osaka, Japan) by refluxing with 
$\mathrm{CHCl}_{3}$, and purification by repeated silica gel column chromatography, ${ }^{1)}$ followed by preparative HPLC. The isolated RHY was identified by comparing its retention time on HPLC, and its NMR, LC-MS, and CD spectra to those of an authentic sample (provided by Tsumura Co., Tokyo, Japan or purchased from Wako Pure Chemical Industries, Ltd., Osaka, Japan). We used RHY at $>99.5 \%$ purity confirmed by HPLC for all experiments.

Animals and RHY Administration Male Wistar rats (8 weeks, 240-250 g) were obtained from Sankyo Labo Service Corp., Inc., Tokyo, Japan. RHY was dissolved in dimethyl sulfoxide (DMSO) for administration unless otherwise indicated. The dosage for oral administration was $37.5 \mathrm{mg} / \mathrm{kg}$ and for intravenous administration was $15 \mathrm{mg} / \mathrm{kg}$. These doses do not refer to the maximal tolerated dose in rats. All animal care and experiments proceeded at the animal experimental center of the University of Toyama in accordance with the guidelines provided by the Life Science Research Center of the same institution. No appreciable side effects were evident in the rats throughout the study.

Preparation of Plasma Samples after Oral Administration The rats were acclimated for $3 \mathrm{~d}$ in metabolic cages with 12-h light intervals. They were fasted overnight with free access to drinking water before oral administration of RHY by a gavage and the fast was continued for $3 \mathrm{~h}$. The rats were anesthetized with an intraperitoneal injection of $12 \mathrm{mg}$ $(64.8 \mathrm{mg} / \mathrm{ml})$ of pentobarbital sodium (Kyoritsu Seiyaku Co., Tokyo, Japan) before collecting blood samples using heparinized (heparin sodium salt solution, 40 units) containers, syringes and needles.

Plasma was separated from blood $(6-8 \mathrm{ml})$ collected from the inferior vena cava of the rats with a syringe at $30 \mathrm{~min}, 1$, $2,3,4,6,8,12,24,36,48,72$ and $96 \mathrm{~h}$ after oral administration, by centrifugation at $2220 \times \boldsymbol{g}$ for $15 \mathrm{~min}$. The plasma was analyzed immediately after the following procedures, or stored at $-22^{\circ} \mathrm{C}$.

Plasma samples $(2.0 \mathrm{ml})$ were lyophilized and then half of the residue was digested with $\beta$-glucuronidase (32000 Sigma units) by agitation at 100 strokes/min (Taitec Personal-11 water bath shaker) at $37^{\circ} \mathrm{C}$ for $12 \mathrm{~h}$ in a buffer $(2.0 \mathrm{ml})$ at $\mathrm{pH}$ 5.0. A 3-ml Waters Sep-Pak ${ }^{\circledR}$ Vac cartridge was washed with methanol $(3.0 \mathrm{ml})$ followed by water $(6.0 \mathrm{ml})$. The incubation mixture was then passed through the cartridge with $3.0 \mathrm{ml}$ of methanol and the eluate was concentrated under vacuum at room temperature to yield a light pink residue that was dissolved in methanol $(4.0 \mathrm{ml})$ and analyzed by LC-MS. The other half of the residue was directly dissolved in methanol $(4.0 \mathrm{ml})$ without enzymatic digestion and analyzed by LCMS.

Preparation of Plasma Samples after Intravenous Administration The tail veins of rats were injected intravenously with RHY and then blood $(0.4 \mathrm{ml})$ was collected from the same vein at $30 \mathrm{~min}, 1,2,3,4,6,8,12,24$ and $36 \mathrm{~h}$. Plasma was separated from the blood samples by centrifugation at $5368 \times \boldsymbol{g}$ for $5 \mathrm{~min}$ and processed as described above, except the volume of lyophilized plasma was $0.2 \mathrm{ml}$, and digestion proceeded using double the amount of the enzyme.

Preparation of Bile Samples after Oral Administration The common bile duct of a rat was cannulated (i.d. $0.58 \mathrm{~mm}$, o.d. $0.96 \mathrm{~mm}$; PE-50). Rhynchophylline was administered orally and then bile $(0.6 \mathrm{ml} / \mathrm{h})$ was collected at 1 -h intervals for $12 \mathrm{~h}$ and lyophilized.

Half of the residue was digested with $\beta$-glucuronidase (60000 Sigma units) in a buffer $(2.0 \mathrm{ml}, \mathrm{pH} 5.0)$ by agitation at $100 \mathrm{strokes} / \mathrm{min}$ for $12 \mathrm{~h}$ at $37^{\circ} \mathrm{C}$. The mixture was processed as described above for plasma samples after oral administration. The other half of the residue was dissolved in methanol $(4.0 \mathrm{ml})$ without enzymatic digestion and analyzed by LC-MS as a control.

Preparation of Urinary and Fecal Samples after Oral Administration Rat urinary $(15-21 \mathrm{ml}$ over a period of $24 \mathrm{~h}$ ), and fecal (15-20 g over $24 \mathrm{~h}$ ) samples were collected at 24-h intervals for $4 \mathrm{~d}$ after oral administration of RHY and stored at $-22{ }^{\circ} \mathrm{C}$ until analysis.

Half of the lyophilized residue of urinary samples $(10.0 \mathrm{ml})$ was digested with $\beta$-glucuronidase (60000 Sigma units $)$ in a buffer $(5.0 \mathrm{ml}, \mathrm{pH} 5.0)$ at $37^{\circ} \mathrm{C}$ for $12 \mathrm{~h}$. The incubation mixture was processed as described above for the plasma samples, except that a $6 \mathrm{ml}$ Waters Sep-Pak ${ }^{\circledR}$ Vac cartridge was used to treat the incubation mixture with $6.0 \mathrm{ml}$ of methanol. The other half of the residue was dissolved in methanol without enzymatic digestion.

All fecal samples collected within $24 \mathrm{~h}$ were ground and extracted with ethyl acetate $(3 \times 200 \mathrm{ml})$. The extracts were pooled and concentrated under vacuum at room temperature to yield a yellow residue that was dissolved in methanol and analyzed by LC-MS.

Controls Control rat blood, bile, urine and feces were collected after the administration of DMSO vehicle and processed as described above.

Isolation of Urinary and Fecal Metabolites We administered RHY $(60 \mathrm{mg} / \mathrm{kg}$ over $8 \mathrm{~h}$ ) orally to four rats for one week. The feces were ground and extracted with methanol and then eluted along with urine samples with methanol through a Diaion HP-20 column $(6 \times 40 \mathrm{~cm})$ that had been washed with water. The concentrated methanol eluate was passed through a column $(2.5 \times 30 \mathrm{~cm})$ containing Sephadex LH-20 and then metabolites in the methanol eluate were separated by repeated preparative HPLC under the following conditions: Cosmosil column, 5C18-AR-II, Waters type, 20 i.d. $\times 250 \mathrm{~mm}$; flow rate, $3.0 \mathrm{ml} / \mathrm{min}$; temperature, $30^{\circ} \mathrm{C}$; detection, UV at $254 \mathrm{~nm}$; elution, stepwise gradient of increasing solvent $\mathrm{B}(0.01 \% \mathrm{v} / \mathrm{v}$ acetic acid in acetonitrile) in solvent $\mathrm{A}(0.01 \% \mathrm{v} / \mathrm{v}$ acetic acid) from 10 to $40 \%$ in $60 \mathrm{~min}, 40$ to $100 \%$ in $20 \mathrm{~min}$ and $100 \%$ for another $40 \mathrm{~min}$.

Isolation of Biliary Metabolites Rat bile was collected from 10 rats after oral RHY administration at a dose of $60 \mathrm{mg} / \mathrm{kg}$ over $8 \mathrm{~h}$ within $1 \mathrm{~d}$, lyophilized and then applied to an $\mathrm{LH}-20$ column $(2.5 \times 30 \mathrm{~cm})$. The methanol eluate was subjected to preparative HPLC under the same conditions described above.

Metabolite M1 (11-Hydroxyrhynchophylline 11- $O$ - $\beta$-DGlucuronide) White amorphous solid, mp $285-290^{\circ} \mathrm{C}$ (uncorrected). $[\alpha]_{\mathrm{D}}^{22}-8.3^{\circ}(c=0.56, \mathrm{MeOH}) . \mathrm{CD} \Delta \varepsilon(\mathrm{nm})$ : +8.7 (288), -6.4 (259), -7.0 (222). HR-FAB-MS $m / z$ : $577.6081\left([\mathrm{M}+\mathrm{H}]^{+}\right.$, Calcd for $\left[\mathrm{C}_{28} \mathrm{H}_{36} \mathrm{~N}_{2} \mathrm{O}_{11}+\mathrm{H}\right]$ : 577.6087). ESI-MS m/z: $577\left([\mathrm{M}+\mathrm{H}]^{+}\right) .{ }^{1} \mathrm{H}-\mathrm{NMR}\left(\mathrm{CD}_{3} \mathrm{OD}\right)$ $\delta$ : 0.89 (3H, t, H-18), $1.16(1 \mathrm{H}$, br m, H-14 $\beta), 1.80(2 \mathrm{H}, \mathrm{m}$, H-19), 2.08 (1H, brm, H-21 $\alpha$ ), 2.10 (1H, m, H-6 $\alpha), 2.21$ (1H, br m, H-20), 2.30 (1H, br m, H-15), 2.36 (1H, br m, H-

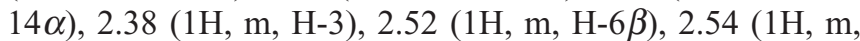
H-5 $\alpha), 3.21$ (1H, m, H-21 $\beta), 3.25$ (1H, m, H-5 $\beta), 3.30(1 \mathrm{H}$, 
m, H-2'), 3.42 (1H, m, H-3'), $3.46\left(1 \mathrm{H}, \mathrm{m}, \mathrm{H}-4^{\prime}\right), 3.68(3 \mathrm{H}$, $\mathrm{s}, \mathrm{H}-23), 3.70\left(1 \mathrm{H}, \mathrm{d}, J_{5^{\prime} 4^{\prime}}=7.6 \mathrm{~Hz}, \mathrm{H}-5^{\prime}\right), 3.78(3 \mathrm{H}, \mathrm{s}$, $\left.\mathrm{OCH}_{3}\right), 4.98\left(1 \mathrm{H}, \mathrm{d}, J_{1^{\prime}, 2^{\prime}}=7.6 \mathrm{~Hz}, \mathrm{H}-1^{\prime}\right), 6.92(1 \mathrm{H}, \mathrm{d}$, $\left.J_{12,10}=1.2 \mathrm{~Hz}, \mathrm{H}-12\right), 7.12\left(1 \mathrm{H}, \mathrm{dd}, J_{10,9}=8.0 \mathrm{~Hz}, J_{10,12}=\right.$ $1.2 \mathrm{~Hz}, \mathrm{H}-10), 7.20\left(1 \mathrm{H}, \mathrm{d}, J_{9,10}=8.0 \mathrm{~Hz}, \mathrm{H}-9\right), 7.35(1 \mathrm{H}, \mathrm{s}$, H-17). ${ }^{13} \mathrm{C}-\mathrm{NMR}\left(\mathrm{CD}_{3} \mathrm{OD}\right) \delta$ : 11.9 (C-18), 24.3 (C-19), 28.5 (C-14), 35.4 (C-6), 40.0 (C-20), 40.9 (C-15), 50.2 (C-23), 55.0 (C-7), 57.2 (C-5), $57.2(\mathrm{C}-21), 63.2\left(\mathrm{OCH}_{3}\right), 71.7(\mathrm{C}-$ $\left.4^{\prime}\right), 74.5$ (C-3), 75.2 (C-2'), 78.2 (C-5'), 78.8 (C-3'), 100.2 (C-12), $100.8\left(\mathrm{C}-1^{\prime}\right), 111.3$ (C-10), 113.7 (C-16), 124.2 (C9), 129.8 (C-8), 141.0 (C-13), 151.4 (C-11), 160.1 (C-17), 169.2 (C-22), 176.8 (C-6'), 182.9 (C-2).

Metabolite M2 (10-Hydroxyrhynchophylline 10- $O$ - $\beta$-DGlucuronide) White amorphous solid, mp $283-286{ }^{\circ} \mathrm{C}$ (uncorrected). $[\alpha]_{\mathrm{D}}^{22}-5.6^{\circ}(c=0.72, \mathrm{MeOH}) . \mathrm{CD} \Delta \varepsilon(\mathrm{nm})$ : +6.9 (292), -3.2 (262), -5.0 (220). HR-FAB-MS $\mathrm{m} / \mathrm{z}$ : $577.6082\left([\mathrm{M}+\mathrm{H}]^{+}\right.$, Calcd for $\left[\mathrm{C}_{28} \mathrm{H}_{36} \mathrm{~N}_{2} \mathrm{O}_{11}+\mathrm{H}\right]$ : 577.6087). ESI-MS $m / z$ : 577.3 or $577.4\left([\mathrm{M}+\mathrm{H}]^{+}\right) .{ }^{1} \mathrm{H}-\mathrm{NMR}$ (CD $\mathrm{CD}_{3} \mathrm{OD} \delta: 1.00(3 \mathrm{H}, \mathrm{t}, \mathrm{H}-18), 1.20(1 \mathrm{H}$, br m, H-14 $\beta), 1.78$ (2H, m, H-19), 1.90 (1H, br m, H-21 $\alpha$ ), 2.02 (1H, m, H-6 $\alpha$ ), 2.20 (1H, br m, H-20), 2.28 (1H, br m, H-15), 2.30 (1H, br m, $\mathrm{H}-14 \alpha), 2.36(1 \mathrm{H}, \mathrm{m}, \mathrm{H}-3), 2.40(1 \mathrm{H}, \mathrm{m}, \mathrm{H}-6 \beta), 2.44(1 \mathrm{H}$, $\mathrm{m}, \mathrm{H}-5 \alpha), 3.15(1 \mathrm{H}, \mathrm{m}, \mathrm{H}-21 \beta), 3.28(1 \mathrm{H}, \mathrm{m}, \mathrm{H}-5 \beta), 3.31$ $\left(1 \mathrm{H}, \mathrm{m}, \mathrm{H}-2^{\prime}\right), 3.44$ (1H, m, H-3'), 3.50 (1H, m, H-4'), 3.62 $(3 \mathrm{H}, \mathrm{s}, \mathrm{H}-23), 3.66\left(1 \mathrm{H}, \mathrm{d}, J_{5^{\prime} 4^{\prime}}=7.6 \mathrm{~Hz}, \mathrm{H}-5^{\prime}\right), 3.73(3 \mathrm{H}, \mathrm{s}$, $\left.\mathrm{OCH}_{3}\right), 4.96\left(1 \mathrm{H}, \mathrm{d}, J_{1^{\prime}, 2^{\prime}}=7.6 \mathrm{~Hz}, \mathrm{H}-1^{\prime}\right), 6.78(1 \mathrm{H}, \mathrm{d}$, $\left.J_{12,11}=7.6 \mathrm{~Hz}, \mathrm{H}-12\right), 7.12\left(1 \mathrm{H}, \mathrm{dd}, J_{11,9}=1.2 \mathrm{~Hz}, J_{11,12}=\right.$ $7.6 \mathrm{~Hz}, \mathrm{H}-11), 7.22$ (1H, d, $\left.J_{9,11}=1.2 \mathrm{~Hz}, \mathrm{H}-9\right), 7.34(1 \mathrm{H}, \mathrm{s}$, $\mathrm{H}-17) .{ }^{13} \mathrm{C}-\mathrm{NMR}\left(\mathrm{CD}_{3} \mathrm{OD}\right) \delta$ : 11.7 (C-18), 24.2 (C-19), 28.3 (C-14), 35.2 (C-6), 40.2 (C-20), 40.3 (C-15), 50.1 (C-23), 55.3 (C-7), 57.1 (C-5), $57.1(\mathrm{C}-21), 63.2\left(\mathrm{OC}_{3}\right), 71.7(\mathrm{C}-$ $\left.4^{\prime}\right), 74.5$ (C-3), $75.0\left(\mathrm{C}-2^{\prime}\right), 78.4\left(\mathrm{C}-5^{\prime}\right), 78.8$ (C-3'), 100.6 $\left(\mathrm{C}-1^{\prime}\right), 110.2$ (C-12), 112.1 (C-16), 114.2 (C-9), 119.6 (C11), 133.9 (C-8), 135.0 (C-13), 150.1 (C-10), 160.9 (C-17), 169.1 (C-22), 176.2 (C-6'), 182.8 (C-2).

Metabolite M3 (11-Hydroxyrhynchophylline) Obtained as a white amorphous solid from methanol, mp 239$241^{\circ} \mathrm{C}$ (uncorrected). $[\alpha]_{\mathrm{D}}^{20}-120.0^{\circ}(c=0.78, \mathrm{MeOH}) . \mathrm{CD}$ $\Delta \varepsilon$ (nm): + 12.0 (289), -4.8 (260), -9.0 (221). HR-FABMS $m / z: 401.4822\left([\mathrm{M}+\mathrm{H}]^{+}\right.$, Calcd for $\left[\mathrm{C}_{22} \mathrm{H}_{28} \mathrm{~N}_{2} \mathrm{O}_{5}+\mathrm{H}\right]$ : 401.4827). ESI-MS $m / z: 401\left([\mathrm{M}+\mathrm{H}]^{+}\right) .{ }^{1} \mathrm{H}-\mathrm{NMR}\left(\mathrm{CD}_{3} \mathrm{OD}\right)$ $\delta: 0.88$ (3H, t, H-18), $1.16(1 \mathrm{H}$, br m, H-14 $\beta), 1.80(2 \mathrm{H}, \mathrm{m}$, H-19), 2.08 (1H, br m, H-21 $\alpha$ ), 2.10 (1H, m, H-6 $\alpha), 2.20$ (1H, br m, H-20), 2.27 (1H, br m, H-15), 2.28 (1H, br m, H-

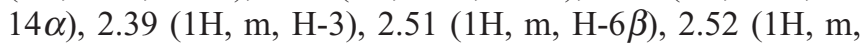
H-5 $\alpha), 3.20$ (1H, m, H-21 $\beta$ ), 3.25 (1H, m, H-5 $\beta), 3.68(3 \mathrm{H}$, s, H-23), $3.80\left(3 \mathrm{H}, \mathrm{s}, \mathrm{OC}_{3}\right), 6.88\left(1 \mathrm{H}, \mathrm{d}, J_{12,10}=1.2 \mathrm{~Hz}, \mathrm{H}-\right.$ 12), $7.08\left(1 \mathrm{H}, \mathrm{dd}, J_{10,9}=8.0 \mathrm{~Hz}, J_{10,12}=1.2 \mathrm{~Hz}, \mathrm{H}-10\right), 7.24$ $\left(1 \mathrm{H}, \mathrm{d}, J_{9,10}=8.0 \mathrm{~Hz}, \mathrm{H}-9\right), 7.37$ (1H, s, H-17). ${ }^{13} \mathrm{C}-\mathrm{NMR}$ $\left(\mathrm{CD}_{3} \mathrm{OD}\right) \delta$ : $11.6(\mathrm{C}-18), 24.1$ (C-19), 28.3 (C-14), $35.3(\mathrm{C}-$ 6), 40.1 (C-20), 40.5 (C-15), 50.2 (C-23), 55.2 (C-7), 57.1 (C-5), 57.1 (C-21), $63.0\left(\mathrm{OCLH}_{3}\right), 74.6$ (C-3), 99.7 (C-12), 111.2 (C-10), 113.1 (C-16), 124.5 (C-9), 129.6 (C-8), 141.6 (C-13), 151.3 (C-11), 159.4 (C-17), 169.0 (C-22), 182.7 (C2).

Metabolite M4 (10-Hydroxyrhynchophylline) Obtained as a white amorphous solid from methanol, mp 233 $237^{\circ} \mathrm{C}$ (uncorrected). $[\alpha]_{\mathrm{D}}^{20}-115.2^{\circ}(c=0.91, \mathrm{MeOH}) . \mathrm{CD}$ $\Delta \varepsilon(\mathrm{nm}):+9.6$ (290), -6.2 (261), -7.20 (222). HR-FABMS $m / z: 401.4823\left([\mathrm{M}+\mathrm{H}]^{+}\right.$, Calcd for $\left[\mathrm{C}_{22} \mathrm{H}_{28} \mathrm{~N}_{2} \mathrm{O}_{5}+\mathrm{H}\right]$ : 401.4827. ESI-MS m/z: $401\left([\mathrm{M}+\mathrm{H}]^{+}\right) .{ }^{1} \mathrm{H}-\mathrm{NMR}\left(\mathrm{CD}_{3} \mathrm{OD}\right)$ $\delta: 0.95$ (3H, t, H-18), $1.18(1 \mathrm{H}$, br m, H-14 $\beta), 1.70(2 \mathrm{H}, \mathrm{m}$, H-19), 1.89 (1H, brm, H-21 $\alpha$ ), 2.00 (1H, m, H-6 $\alpha), 2.12$ (1H, br m, H-20), 2.25 (1H, br m, H-15), 2.33 (1H, br m, H-

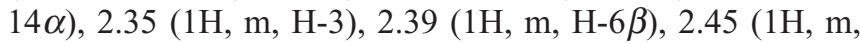
$\mathrm{H}-5 \alpha), 3.15(1 \mathrm{H}, \mathrm{m}, \mathrm{H}-21 \beta), 3.28(1 \mathrm{H}, \mathrm{m}, \mathrm{H}-5 \beta), 3.60(3 \mathrm{H}$, s, H-23), $3.72\left(3 \mathrm{H}, \mathrm{s}, \mathrm{OCH}_{3}\right), 6.86\left(1 \mathrm{H}, \mathrm{d}, J_{12,11}=7.6 \mathrm{~Hz}, \mathrm{H}-\right.$ 12), 7.07 ( $\left.1 \mathrm{H}, \mathrm{dd}, J_{11,9}=1.2 \mathrm{~Hz}, J_{11,12}=7.6 \mathrm{~Hz}, \mathrm{H}-11\right), 7.18$ $\left(1 \mathrm{H}, \mathrm{d}, J_{9,11}=1.2 \mathrm{~Hz}, \mathrm{H}-9\right), 7.33(1 \mathrm{H}, \mathrm{s}, \mathrm{Hz}, \mathrm{H}-17) .{ }^{13} \mathrm{C}-\mathrm{NMR}$ $\left(\mathrm{CD}_{3} \mathrm{OD}\right) \delta$ : 11.6 (C-18), 24.1 (C-19), 28.2 (C-14), 35.1 (C6), 39.7 (C-20), 40.4 (C-15), 50.0 (C-23), 55.1 (C-7), 57.3 (C-5), 57.3 (C-21), $63.1\left(\mathrm{OCH}_{3}\right), 74.4$ (C-3), 110.4 (C-12), 112.5 (C-16), 114.0 (C-9), 119.5 (C-11), 134.0 (C-8), 134.7 (C-13), 149.7 (C-10), 161.7 (C-17), 169.2 (C-22), 182.9 (C2).

Preparation of Brain Samples Each rat was intraperitoneally anesthetized with $26 \mathrm{mg}$ of pentobarbital sodium at $3 \mathrm{~h}$ after oral RHY administration with a dose of $37.5 \mathrm{mg} / \mathrm{kg}$. The brain including the cerebrum, cerebellum and about $0.5 \mathrm{~cm}$ of medulla oblongata was removed en bloc after decapitation. Traces of blood on the brain surface were washed with saline. Whole brains (wet weight $1.965 \pm 0.076 \mathrm{~g}$; means \pm S.D.; $n=3$ ) were homogenized and sonicated in methanol $(5 \mathrm{ml} \times 3)$ for $5 \mathrm{~min}$. The mixture was separated by centrifugation at $2220 \times \boldsymbol{g}$ for $5 \mathrm{~min}$. The supernatant was pooled and concentrated under vacuum at room temperature to afford a white residue that was dissolved in methanol $(8.0 \mathrm{ml})$, passed through a $0.45 \mathrm{~mm}$ filter and analyzed by LC-MS. The wet weight of the rat brain administered with vehicle (control) was $2.036 \pm 0.088 \mathrm{~g}$.

Incubation of RHY with Rat Liver Microsomes The reaction mixture $(1.0 \mathrm{ml})$ comprised $100.0 \mu \mathrm{M}$ RHY, pooled rat liver microsomes (protein $1.0 \mathrm{mg}$ ), and $5.0 \mathrm{~mm} \mathrm{MgCl}_{2}$ in $0.1 \mathrm{M}$ phosphate buffered saline (PBS) buffer ( $\mathrm{pH} 7.4)$. The reaction was triggered by $2.0 \mathrm{~mm} \beta$-NADPH after preheating all of them for $3 \mathrm{~min}$, and continued at $37^{\circ} \mathrm{C}$ under agitation by 100 strokes per minute for $1 \mathrm{~h}$. The reaction was terminated by adding ice-cold ethyl acetate $(1 \mathrm{ml})$ and then incubation mixture was extracted with ethyl acetate $(3 \times 1 \mathrm{ml}$, including the terminator). The extracts were pooled and evaporated in vacuo to yield a residue that was dissolved in methanol for analysis by LC-MS.

Specific inhibitors were added to the incubation mixture to investigate the isozyme hydroxylation on RHY separately. The inhibitors were $400.0 \mu \mathrm{M}$ SKF (nonspecific inhibitor of CYP), ${ }^{8,9)} 25.0 \mu \mathrm{M}$ NAP (inhibitor of CYP1A1/2), ${ }^{10,11)}$ $200.0 \mu \mathrm{M}$ CIM (inhibitor of CYP2C), ${ }^{9)} 25.0 \mu \mathrm{M}$ QUI (inhibitor of CYP2D), ${ }^{12}$ and $200.0 \mu \mathrm{M}$ ERY (inhibitor of CYP3A). ${ }^{11)}$ Both RHY and the inhibitors were dissolved in DMSO and diluted in the reaction mixture so that the final DMSO concentrations were $<1 \%(\mathrm{v} / \mathrm{v})$. The reaction was started by adding RHY, and terminated to prepare analytical samples as described above.

Glucuronidation of Hydroxylated RHY Rat liver microsomes (1.0 mg protein) were activated with alamethicin $(50.0 \mathrm{mg})$ in $0.1 \mathrm{M}$ PBS buffer $(\mathrm{pH} 7.4,0.5 \mathrm{ml})$ on ice for 15 min. ${ }^{12,13)}$ A mixture of rat liver microsomes, $\beta$-NADPH (2.0 mM), RHY, alamethicin, and $\mathrm{MgCl}_{2}(5.0 \mathrm{~mm})$ was incubated at $37^{\circ} \mathrm{C}$ for $3 \mathrm{~min}$ in the same buffer (total $1.0 \mathrm{ml}$ ) and then UDPGA $(5.0 \mathrm{~mm})$ was added to start the reaction. The same volume of ice-cold methanol was added to stop the reaction at $2 \mathrm{~h}$. The mixture was separated by centrifugation at 
$5368 \times \boldsymbol{g}$ for $5 \mathrm{~min}$, passed through a $0.45 \mu \mathrm{m}$ filter and then the filtrate was analyzed by LC-MS. A portion of the filtrate after solvent evaporation was agitated at 100 strokes per min at $37^{\circ} \mathrm{C}$ for $6 \mathrm{~h}$ with $\beta$-glucuronidase (5000 Sigma units) in $1.0 \mathrm{ml}$ of buffer ( $\mathrm{pH} 5.0)$. The reaction mixture was separated by centrifugation at $5368 \times \boldsymbol{g}$ for $5 \mathrm{~min}$ to yield a supernatant that was analyzed by LC-MS.

LC-ESI-Ion Trap MS Measurements Both in vivo and in vitro samples were analyzed using an Agilent 1100 series HPLC system coupled with a Bruker Daltonics ${ }^{\circledR}$ Esquire $3000^{\text {plus }}$ mass spectrometer. Integrated LC-MS control and data were processed using the Agilent ChemStation for the LC-MS system and Bruker Daltonics Esquire 5.1 (Esquire Control Version 5.1, and DataAnalysis Version 3.1).

The samples were applied to a Cosmosil packed column (5C18-MS-II, 4.6 i.d. $\times 150 \mathrm{~mm}$ ) at $30^{\circ} \mathrm{C}$, and UV detection was set at 245, 254, 230, 208 and $280 \mathrm{~nm}$. The elution system comprised an increase of solvent B $(0.01 \% \mathrm{v} / \mathrm{v}$ acetic acid in $\left.\mathrm{CH}_{3} \mathrm{CN}\right)$ from 20 to $70 \%$ in solvent $\mathrm{A}(0.01 \% \mathrm{v} / \mathrm{v}$ acetic acid) within $15 \mathrm{~min}$, then to $100 \%$ within $5 \mathrm{~min}$ at a flow rate of $1.0 \mathrm{ml} / \mathrm{min}$ unless indicated otherwise. All samples were passed through a $0.45 \mu \mathrm{m}$ filter before analysis. The injection volume was $2.0 \mu$ f for LC-MS. Through a splitting device, $20 \%$ of the eluate from a diode array detector was introduced to atmospheric pressure interface-electrospray ionization (API-ESI) for total ion monitoring (TIM) or selective ion monitoring (SIM). The fragmentation cut-off was set at $27 \%$ of the precursor mass. The scan range of the ion trap was from $m / z 50$ to 1000 in the positive ion mode, the nebulizer was set at $50 \mathrm{psi}$, dry gas at $10.01 / \mathrm{min}$ and the dry temperature was $360^{\circ} \mathrm{C}$.

Both RHY and its metabolites were quantified by LC-MS. Calibration curves of RHY and its metabolites were constructed based on areas in the extracted ion chromatogram (EIC) against known concentrations of each in methanol. The correlation coefficient $r^{2}$ was $>0.999$ in a concentration range from $4.0 \times 10^{-10}$ to $4.0 \times 10^{-7} \mathrm{~mol} / 1$.

Verification of the Analysis Method Quantification of RHY and its metabolites was carried out by the above described LC-ESI-Ion Trap MS method. The accuracy and repeatability of this quantification method were verified by recovery and precision experiments. The recovery of RHY and its metabolites was examined by adding precise amounts of a substrate or its metabolites $\left(4.0 \times 10^{-10}, 1.2 \times 10^{-8}\right.$, and $4.0 \times 10^{-7} \mathrm{~mol} / 1$, respectively) to body fluids $(6.0 \mathrm{ml}$ blood from inferior vena cava, $0.4 \mathrm{ml}$ blood from tail vein, and $0.6 \mathrm{ml}$ bile) and excretions $(20.0 \mathrm{ml}$ urine, and $20.0 \mathrm{~g}$ feces $)$, and then measuring the respective concentrations by LC-MS. The recoveries from five analyses varied from 95.2 to $102.5 \%$.

The precision of the analysis of RHY and its metabolites was examined by comparing the results of intra- and interday assays with relative standard deviation (RSD) values. The RSD values for intra-day (5 measurements on the same day for each sample) and inter-day ( 5 measurements per day for each sample for 5 continuous days) assay were both $<5.0 \%$.

All of the data in Table 2, Figs. 2, 5, 6, 7 and 10, are shown as means \pm S.D. $(n=3)$, unless otherwise indicated.

Pharmacokinetic Parameters Calculation The elimination rate constant $(k)$ was determined as the absolute value

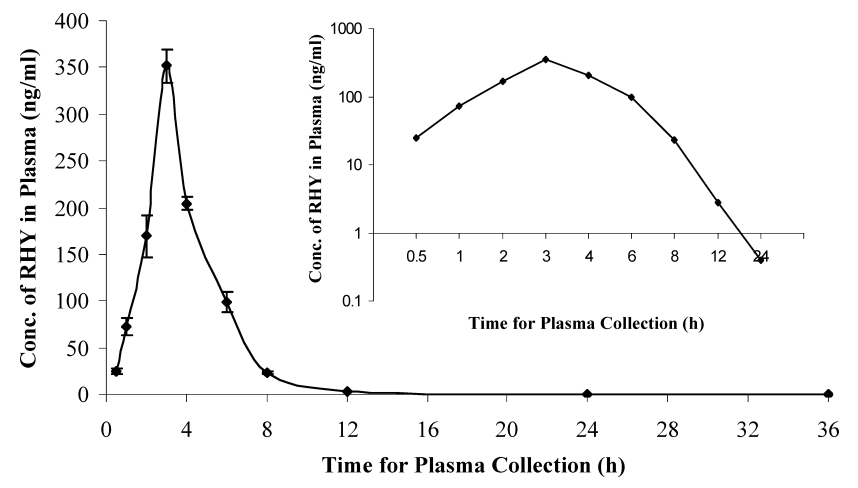

Fig. 2. Time Course of RHY in Rat Plasma after Oral Administration

After oral administration of $37.5 \mathrm{mg} / \mathrm{kg}$, RHY concentrations in plasma were quantified by LC-MS (EIC) monitored at $m / z 385 \pm 0.5$ in the positive ion mode.

of the slope of a least-square linear regression of the logarithmic plasma concentration-time curve of RHY. The elimination half-life $\left(t_{1 / 2}\right)$ was calculated as $0.693 / k$. The total body clearance $(C L)$ was obtained as Dose i.v. $/ A U C_{0-\infty, \text { i.v. }}$ The apparent volume of distribution $(V)$ was calculated as $C L / k$. The maximum plasma concentration $\left(C_{\max }\right)$ of RHY and the time $\left(t_{\max }\right)$ to reach $C_{\max }$ were observed values. The area under the plasma concentration-time curve $\left(A U C_{0-\infty}\right)$ from time zero to infinite was calculated as the sum of $A U C_{0-24 \mathrm{~h}}$ and $C_{24 \mathrm{~h}} / k$ by the linear trapezoidal method. ${ }^{7,14,15)}$ The absolute bioavailability $(F)$ was calculated as $\left(A U C_{0-\infty, p . o .} \times\right.$ Dose $\left._{\text {i.v. }}\right) /\left(A U C_{0-\infty, \text { i.v. }} \times\right.$ Dose $\left._{\text {p.o. }}\right)$.

\section{RESULTS AND DISCUSSION}

Plasma RHY After oral administration of RHY at a dose of $37.5 \mathrm{mg} / \mathrm{kg}$ to rats, concentrations of RHY and its metabolites in plasma were monitored by LC-MS. The unchanged RHY was detected in plasma (ESI-MS $\mathrm{m} / \mathrm{z}: 385$ $[\mathrm{M}+\mathrm{H}]^{+}$) at a retention time of $4.8 \mathrm{~min}$ in the EIC at $\mathrm{m} / \mathrm{z}$ 385. The compound was identified by comparing the retention time and MS spectra including $\mathrm{MS}^{2}$ and $\mathrm{MS}^{3}$ with those of an authentic sample (data not shown). The time course of RHY in plasma is shown in Fig. 2. The RHY concentration reached a maximum at $3 \mathrm{~h}$ (observed value), and then abruptly decreased within $8 \mathrm{~h}$. However, metabolites including the isomeric form ISOR were undetectable. On the other hand, RHY and ISOR were both detected in rat plasma as unchanged forms after the intravenous administration of $15 \mathrm{mg} / \mathrm{kg}$. These compounds were eluted at retention times of 4.6 and $4.8 \mathrm{~min}$ in the EIC at $m / z 385$ (Fig. 3), and their MS spectra (ESI-MS m/z: $385[\mathrm{M}+\mathrm{H}]^{+}$) were almost identical. Both compounds were finally identified by comparing their retention times to those of authentic samples.

RHY and Metabolites in Bile Rhynchophylline and its metabolites M1 and M2 were detected in rat bile by LC-MS after the oral administration of $37.5 \mathrm{mg} / \mathrm{kg}$ of RHY. Both M1 and M2 had the same quasi-molecular ion peak at $\mathrm{m} / \mathrm{z} 577$ $\left([\mathrm{M}+\mathrm{H}]^{+}\right)$in the ESI-MS spectrum (Figs. 4b, c, Table 1), but different retention times of 3.5 and $4.1 \mathrm{~min}$, respectively, in the EIC at $m / z 577$ (Fig. 4a). M1 and M2 were quantitatively converted to M3 and M4, respectively, by $\beta$-glucuronidase (Fig. 4d), and their MS spectra both showed $\mathrm{m} / \mathrm{z} 401$ $[\mathrm{M}+\mathrm{H}]^{+}$(Figs. 4e, f, Table 1), which was identical to those 

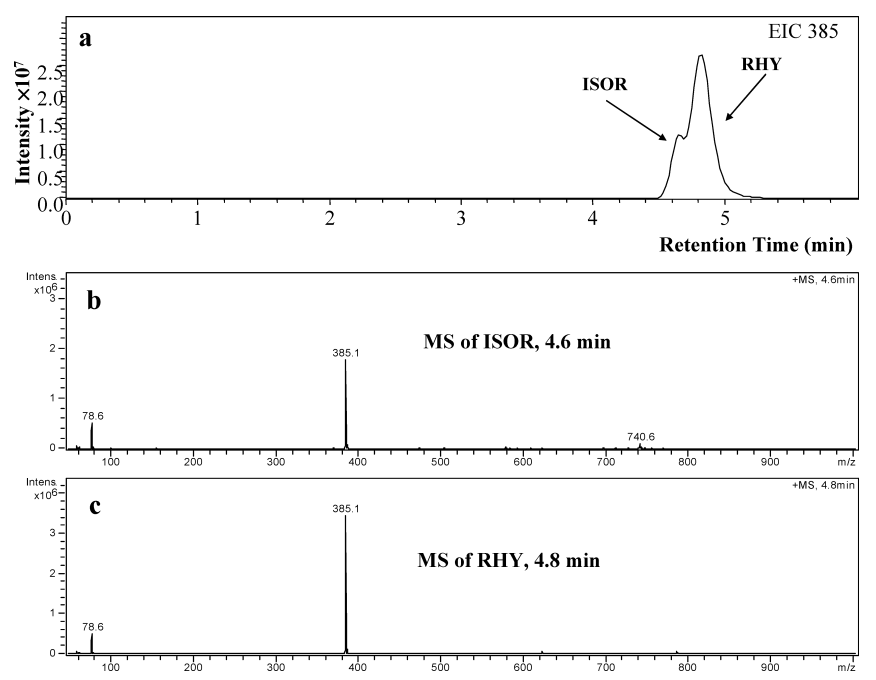

Fig. 3. LC-MS (EIC) Elution Profile Monitored at $m / z 385 \pm 0.5$ and Mass Spectra of ISOR and RHY Detected in a Plasma Sample $2 \mathrm{~h}$ after Intravenous RHY Administration
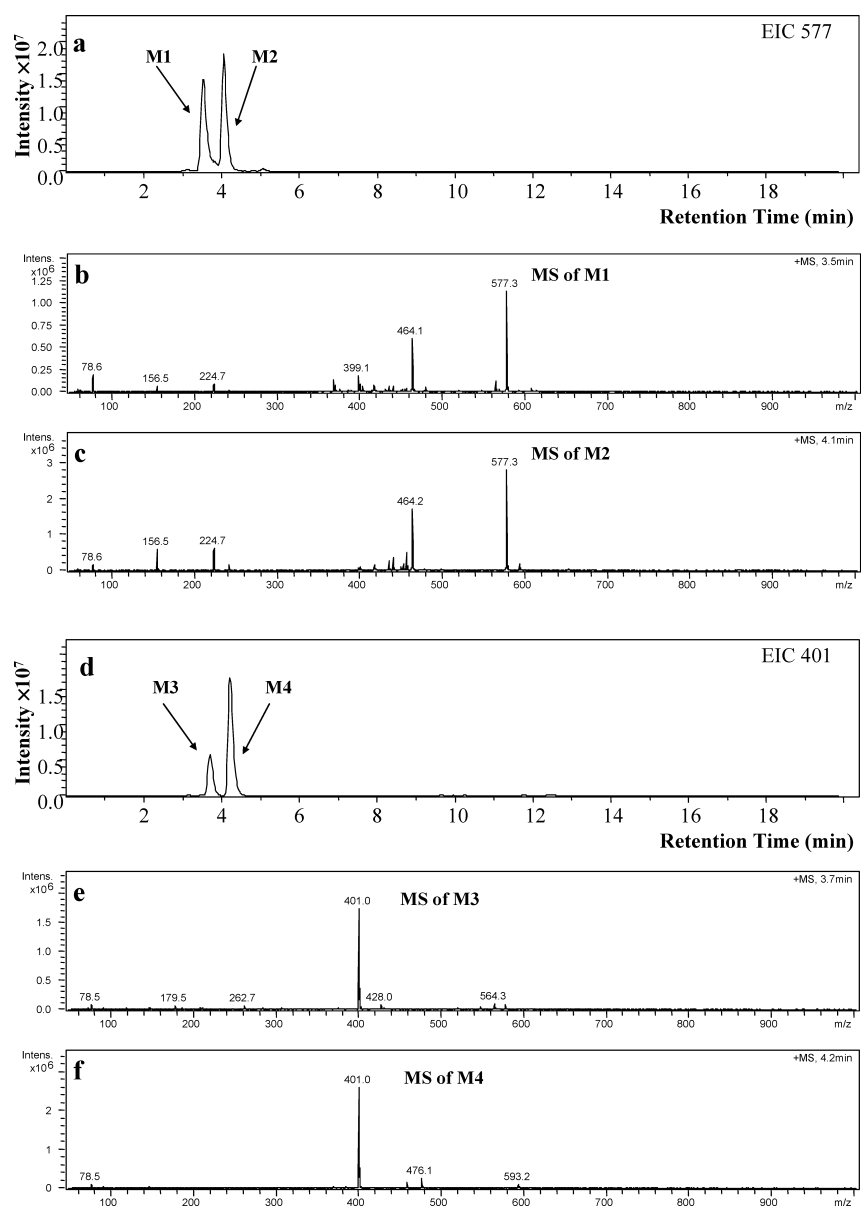

Fig. 4. LC-MS (EIC) Elution Profiles Monitored at $m / z$ 577 \pm 0.5 (M1 and M2) in Bile Sample Collected 2 to $3 \mathrm{~h}$ after Oral RHY Administration and at $\mathrm{m} / z$ 401 \pm 0.5 (M3 and M4) for That Digested with $\beta$-Glucuronidase

of metabolites excreted into urine and feces. The accumulation curves of RHY and its metabolites excreted into bile after oral administration are shown in Fig. 5. Increasing amounts of M1 and M2 were excreted into the bile within $6 \mathrm{~h}$
Table 1. Retention Times and Major Mass Spectral Data in Positive Ion Mode

\begin{tabular}{lcccc}
\hline \hline & \multirow{2}{*}{$\begin{array}{c}\text { Retention } \\
\text { time (min) }\end{array}$} & \multicolumn{3}{c}{ Mass spectral data $(m / z)$} \\
\cline { 3 - 5 } & & MS & MS/MS & MS $^{3}$ \\
\hline M1 & 3.5 & 577 & 401 & 369,337 \\
M2 & 4.1 & 577 & 401 & 369,337 \\
M3 & 3.7 & 401 & 369,337 & 337,281 \\
M4 & 4.2 & 401 & 369,337 & 337,281 \\
ISOR & 4.6 & 385 & 353 & 321,269 \\
RHY & 4.8 & 385 & 353 & 321,269 \\
\hline
\end{tabular}

Main fragments are listed.

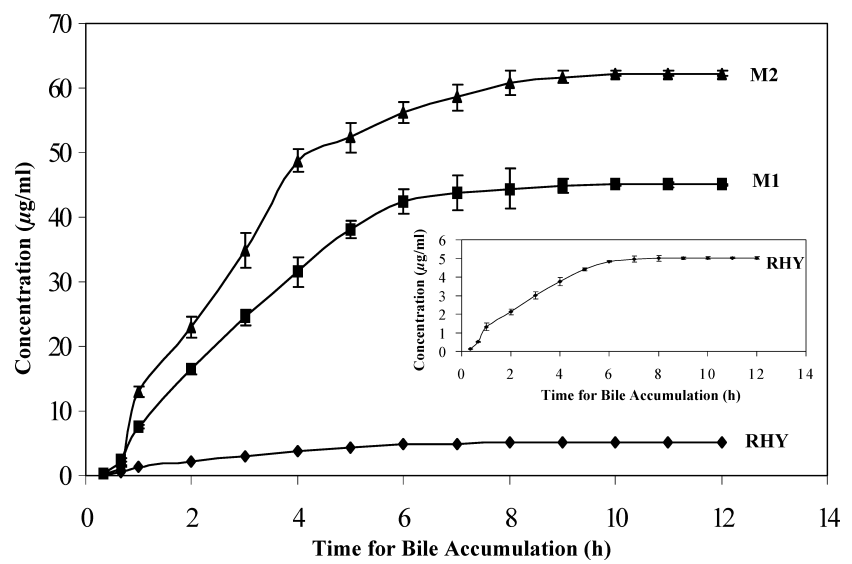

Fig. 5. Cumulative Curves of RHY, M1 and M2 in Rat Bile after Oral RHY Administration

and then reached plateaus. About $5.9 \%$ of the administered dose of RHY was excreted into bile within $12 \mathrm{~h}$, during which 39.2 and $54.2 \%$ of RHY were transformed to M1 and M2, respectively.

RHY and Its Metabolites in Urine and Feces Each of RHY, M3 and M4 were detected in rat urine and feces by LC-MS in their free forms. The excretion of RHY, M3 and M4 into urine and feces is shown in Figs. 6 and 7, respectively. The amount of RHY excreted into feces $(20.0 \mathrm{~g}$, in $24 \mathrm{~h})$ was 5 -fold higher than that excreted into urine $(20.0 \mathrm{ml}$, within $24 \mathrm{~h}$ ). A total of $9.4 \%$ of the administered RHY was converted to M3 and M4 at a ratio of $47: 53$. Relatively small amounts of M3 and M4 were detected in urine and feces.

Distribution of RHY in the Brain After the oral administration of $37.5 \mathrm{mg} / \mathrm{kg}$ of RHY to rats, $0.650 \pm 0.018 \mathrm{ng} / \mathrm{g}$ of RHY was detected in the brain by EIC monitored at $m / z 385$ (Fig. 8) at $3 \mathrm{~h}$ after administration. However, metabolites and RHY isomers were undetectable in the brain sample.

Structures of Metabolites Rat urine and feces were collected after repeated administration of RHY to determine the structure of metabolites M3 and M4. Repeated column chromatography yielded two pure compounds with a quasi-molecular ion peak at $401[\mathrm{M}+\mathrm{H}]^{+}$, which was 16 mass units higher than that of RHY, suggesting that they were monohydroxylated. M3 was assigned the molecular formula $\mathrm{C}_{22} \mathrm{H}_{28} \mathrm{~N}_{2} \mathrm{O}_{5}$ by HR-FAB-MS. The ${ }^{1} \mathrm{H}-\mathrm{NMR}$ spectrum of M3 was similar to that of RHY, except for an aromatic region, in which an ABX-type signal appeared. Since a proton signal at $\delta 7.24\left(1 \mathrm{H}, \mathrm{d}, J_{910}=8.0 \mathrm{~Hz}, \mathrm{H}-9\right)$ neighboring a signal at $\delta$ $7.08(\mathrm{H}-10)$ correlated with a carbon signal at $\delta 55.2(\mathrm{C}-7)$ in 


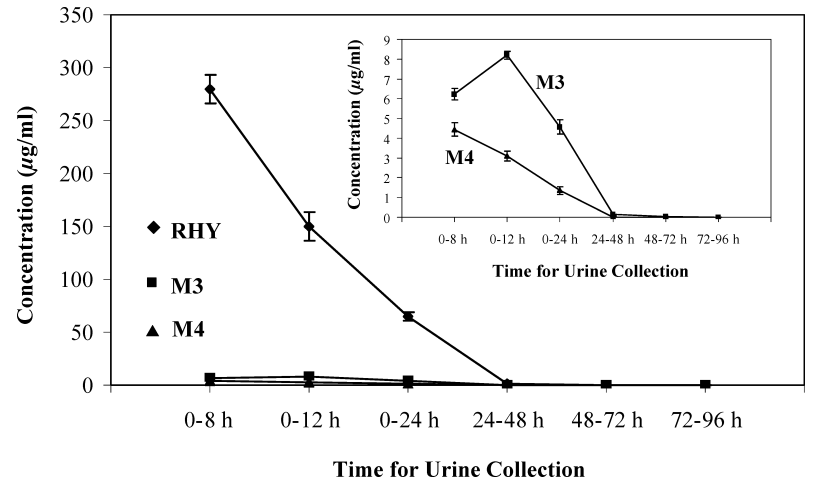

Fig. 6. Excretion Curves of RHY, M3, and M4 into Rat Urine after Oral RHY Administration $(n=3)$

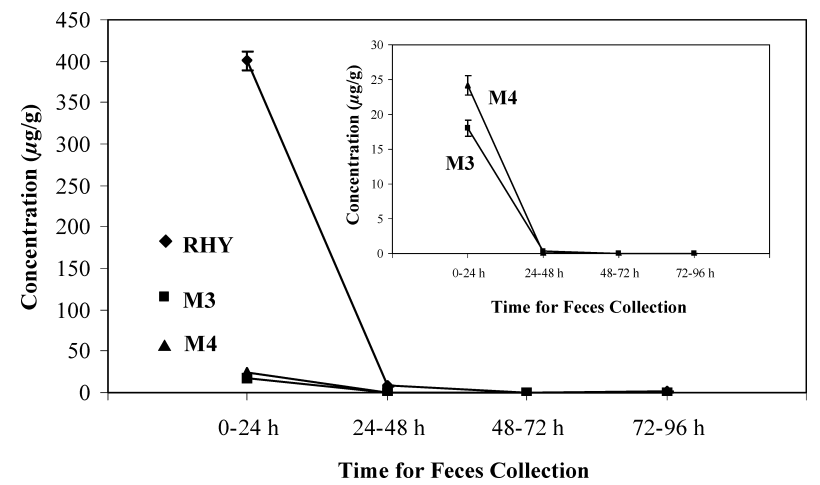

Fig. 7. Excretion Curves of RHY, M3, and M4 into Rat Feces after Oral RHY Administration $(n=3)$
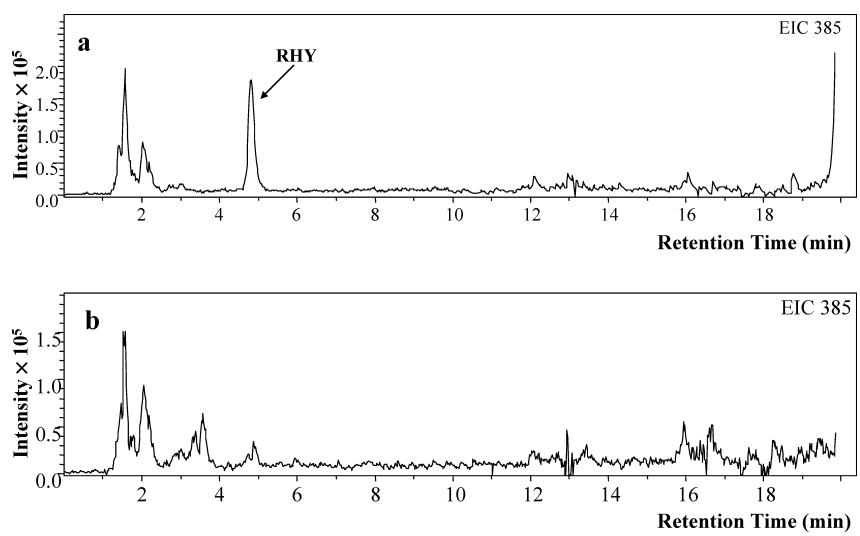

Fig. 8. LC-MS (EIC) Elution Profiles of Rat Brain Sample (a) Collected at $3 \mathrm{~h}$ after Oral Administration and Control Sample (b) Monitored at $\mathrm{m} / \mathrm{z}$ $385 \pm 0.5$ (RHY)

the HMBC experiment (Fig. 9), we concluded that M3 was 11-hydroxyrhynchophylline. Similarly, M4 was assigned the molecular formula $\mathrm{C}_{22} \mathrm{H}_{28} \mathrm{~N}_{2} \mathrm{O}_{5}$ by HR-FAB-MS. The ${ }^{1} \mathrm{H}-$ NMR spectrum of M4 was similar to that of M3 with an ABX-type signal in the aromatic region. The heteronuclear multiple bond coherence (HMBC) spectrum revealed a significant correlation between a proton signal at $\delta 7.18(1 \mathrm{H}, \mathrm{d}$, $\left.J_{9,11}=1.2 \mathrm{~Hz}, \mathrm{H}-9\right)$ and a carbon signal at $\delta 149.7$ (C-10), or at $\delta 55.1(\mathrm{C}-7)$, indicating a hydroxy group attached at $\mathrm{C}-10$ in the aromatic ring. We consequently determined M4 as 10hydroxyrhynchophylline (Fig. 9).

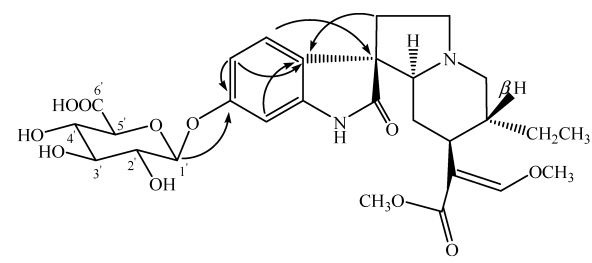

M1

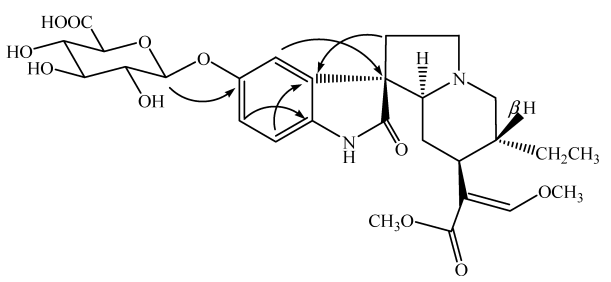

M2

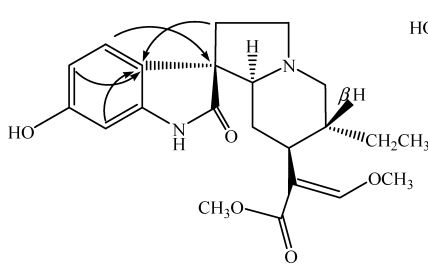

м3

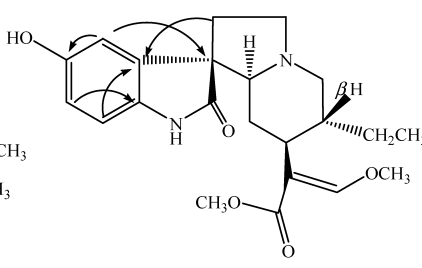

M4
Fig. 9. Structures M1-4 with Key HMBC

Since M1 and M2 were converted to M3 and M4, respectively, by $\beta$-glucuronidase digestion and the difference in molecular units between the latter metabolites corresponded to the liberation of the glucuronic acid residue $\mathrm{C}_{6} \mathrm{H}_{8} \mathrm{O}_{6}$, we speculated that $\mathrm{M} 1$ and $\mathrm{M} 2$ are glucuronides of $\mathrm{M} 3$ and $\mathrm{M} 4$. M1 was assigned the molecular formula $\mathrm{C}_{28} \mathrm{H}_{36} \mathrm{~N}_{2} \mathrm{O}_{11}$ by HRFAB-MS. The ${ }^{1} \mathrm{H}$ - and ${ }^{13} \mathrm{C}-\mathrm{NMR}$ spectra of $\mathrm{M} 1$ and $\mathrm{M} 2$ resembled that of the basic 11-hydroxyrhynchophylline and 10hydroxyrhynchophylline structures, respectively, except for signals due to the glucuronide moiety. The appreciable correlation between a proton signal at $\delta 4.98(1 \mathrm{H}, \mathrm{d}, J=7.6 \mathrm{~Hz}, \mathrm{H}-$ $\left.1^{\prime}\right)$ and a carbon signal at $\delta 151.4(\mathrm{C}-11)$ in the HMBC experiment of M1 indicated that a glucuronic acid residue is attached to C-11 of 11-hydroxyrhynchophylline. From the coupling constant $J_{1^{\prime}, 2^{\prime}}=7.6 \mathrm{~Hz}$ of an anomeric proton of the sugar, we determined the structure of M1 as 11-hydroxyrhynchophylline 11-O- $\beta$-D-glucuronide (Fig. 9). Similarly, M2 was assigned the molecular formula $\mathrm{C}_{28} \mathrm{H}_{36} \mathrm{~N}_{2} \mathrm{O}_{11}$ by HRFAB-MS. The appreciable correlation of a proton signal at $\delta$ $4.96\left(1 \mathrm{H}, \mathrm{d}, J=7.6 \mathrm{~Hz}, \mathrm{H}-1^{\prime}\right)$ and a carbon signal at $\delta 150.1$ (C-10) in the HMBC experiment of M2 indicated that a glucuronic acid residue is attached to C-10 of 10-hydroxyrhynchophylline. Based on the coupling constant $J_{1^{\prime}, 2^{\prime}}=7.6 \mathrm{~Hz}$ of an anomeric proton of the sugar, we concluded that M2 was 10-hydroxyrhynchophylline 10- $O$ - $\beta$-D-glucuronide (Fig. 9).

The absolute configuration of the asymmetric centers at $\mathrm{C}$ 3 and C-7 for M1 to M4 were assigned to $S$ and $R$, respectively, by comparing their CD spectra with that of RHY. ${ }^{16)}$

Main Pharmacokinetic Parameters for RHY in Rats The pharmacokinetic parameters for RHY in rats are shown in Table 2.

Hydroxylation of RHY by Rat Liver Microsomes Rhynchophylline was hydroxylated at the aromatic ring to 
Table 2. Main Pharmacokinetic Parameters for RHY in Rats

\begin{tabular}{|c|c|c|c|}
\hline Parameter & Units & $\begin{array}{l}\text { Intravenous administration } \\
\qquad 15.0 \mathrm{mg} / \mathrm{kg}\end{array}$ & $\begin{array}{c}\text { Oral administration } \\
37.5 \mathrm{mg} / \mathrm{kg}\end{array}$ \\
\hline$k$ & $\min ^{-1}$ & $(8.521 \pm 0.19) \times 10^{-3}$ & \\
\hline$t_{1 / 2}$ & $\min$ & $81.33 \pm 1.8$ & \\
\hline$V$ & $1 / \mathrm{kg}$ & $(1.009 \pm 0.0069) \times 10^{-1}$ & \\
\hline$C L$ & $1 \cdot \mathrm{kg}^{-1} \cdot \min ^{-1}$ & $(8.597 \pm 0.13) \times 10^{-4}$ & \\
\hline$t_{\max }$ & $\min$ & & $180.0 \pm 0.82$ \\
\hline$C_{\max }$ & $\mathrm{ng} / \mathrm{ml}$ & & $351.5 \pm 1.2$ \\
\hline$A U C_{0-\infty}$ & $\mu \mathrm{g} \cdot \mathrm{ml}^{-1} \cdot \min$ & $(17.44 \pm 0.27) \times 10^{3}$ & $191.3 \pm 4.2$ \\
\hline
\end{tabular}

yield M3 and M4, together with their glucuronides M1 and M2 by rat liver microsomes. Independent experiments showed that M3 and M4 were converted to M1 and M2, respectively, in yields of about $10 \%$ by rat liver microsomes in the presence of UDPGA. Furthermore, digestion with $\beta$-glucuronidase returned these products to the original M3 and M4, respectively. These findings confirmed that hepatic enzymes metabolized RHY in rats.

The hydroxylation of RHY by rat liver microsomes was significantly inhibited by SKF-525A (nonspecific inhibitor of CYP) (Fig. 10). Neither of the hydroxylated metabolites of RHY was detected in the absence of $\beta$-NADPH. The amounts of M3 and M4 were appreciably increased by an increase in protein concentrations from 0.25 to $2.0 \mathrm{mg} / \mathrm{ml}$ or incubation periods from 10 to $120 \mathrm{~min}$ (data not shown). All of this evidence indicates that CYP in rat liver microsomes was responsible for the RHY hydroxylation. The hydroxylation of RHY by rat liver microsomes was decreased by 30 $90 \%$ in the presence of specific inhibitors such as QUI, NAP and CIM, respectively, but not altered in the presence ERY. Thus, CYP2D, CYP1A1/2, and CYP2C, but not CYP3A, might participate in RHY hydroxylation. Notably, the inhibitory ratios of QUI, NAP, and CIM varied between M3 and M4.

In conclusion, RHY was detected in rat plasma, bile, urine, and feces after oral administration without being conjugated. No metabolites were detected in rat plasma by LC-MS, whereas 10- and 11-hydroxyrhynchophyllines were detected in urine and feces. Two metabolites conjugated with $\beta$-D-glucuronic acid were detected in rat bile. Due to the extremely low concentrations of RHY in rat plasma compared to those in bile after oral administration, and its metabolites being detected in bile, we speculate that a significant hepatic first-pass effect occurs in rats in vivo. Since $12.6 \%$ of the administered dose was excreted into urine regardless of the extremely low $F$ value of $0.439 \%$, RHY might be rapidly eliminated from the bloodstream into bile, compared to gastrointestinal absorption. RHY is reported to undergo isomerization at the spiro center to form ISOR in vitro through a proposed mechanism including retro-Mannich ring opening, rotation and Mannich ring closure. ${ }^{17)}$ However, no isomerization was observed in vivo after oral administration. On the other hand, isomerization was observed in vivo after intravenous administration. Considering this phenomenon together with the extremely low $F$ value, we speculated that most RHY bound with certain proteins in the gastrointestinal tract before entering circulation. The protein-bound form prevented RHY from isomerization and made the detectable concentration of RHY in bloodstream very low. However,
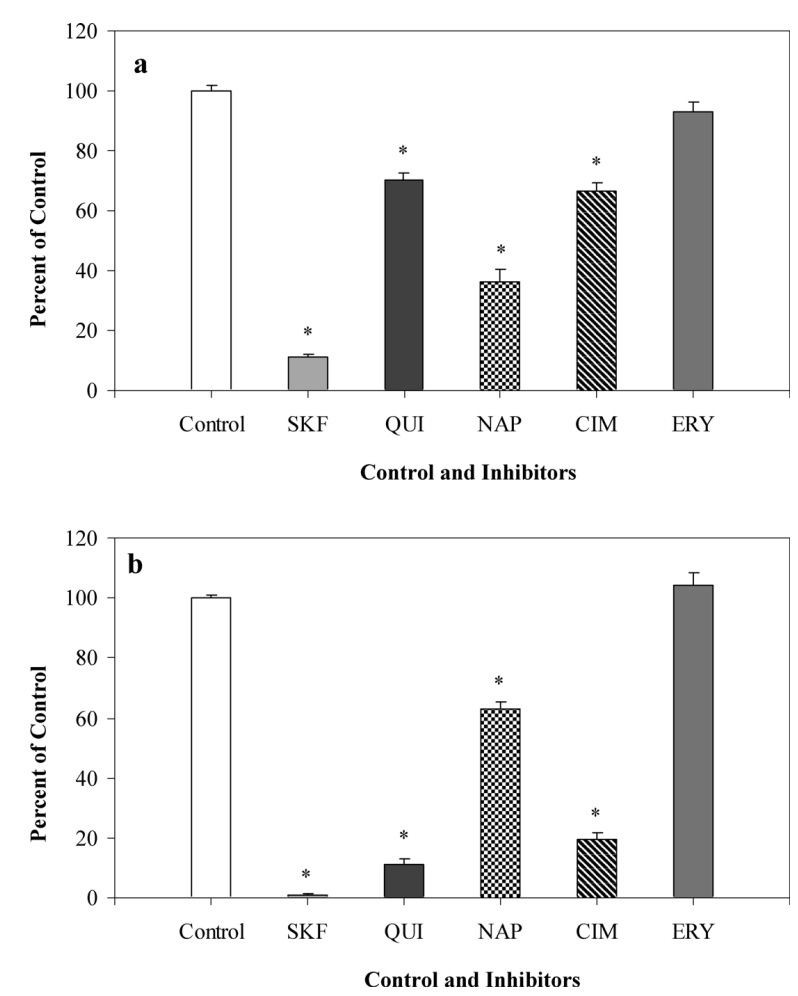

Fig. 10. Effects of Isozyme Inhibitors on Hydroxylation of RHY to M3 (a) and M4 (b)

* Significant value at $p<0.01$ (Student's $t$-test). SKF (nonspecific CYP inhibitor), QUI (CYP2D inhibitor), NAP (CYP1A1/2 inhibitor), CIM (CYP2C inhibitor) and ERY (CYP3A inhibitor).

further experiments are needed to confirm this speculation. The detection of RHY in rat brain shows that RHY can pass through the blood-brain barrier (BBB), although in limited amounts.

The incubation of RHY with rat liver microsomes in vitro verified that CYP1A1/2, CYP2C, and CYP2D are involved in RHY hydroxylation in the rat liver.

The finding that RHY can pass through BBB to rat brain provided evidence from chemistry opinion of view that RHY may exert biological effect on central nervous system, which agreed with the pharmacological reports. ${ }^{4-6)}$ Various pharmacological effects of RHY including the recovery of spacecognition activity should be taken into account when considering the actions of RHY on the central nervous system.

Acknowledgments We appreciate Tsumura Co. (Tokyo, Japan) for their financial support and for providing authentic samples isolated from Uncaria plants. WW thanks the Nippon Foundation for financial support.

\section{REFERENCES}

1) Laus G., Keplinger D., J. Chromatogr. A, 662, 243-249 (1994).

2) Kang T.-H., Murakami Y., Takayama H., Kitajima M., Aimi N., Watanabe H., Matsumoto K., Life Sci., 76, 331-343 (2004).

3) Matsumoto K., Morishige R., Murakami Y., Tohda M., Takayama H., Sakakibara I., Watanabe H., Eur. J. Pharmacol., 517, 191-199 (2005).

4) Zhang W.-B., Chen C.-X., Sim S.-M., Kwan C.-Y., Naunyn-Schmiedeberg's Arch. Pharmacol., 369, 232-238 (2004).

5) Chou C.-H., Gong C.-L., Chao C.-C., Lin C.-H., Kwan C.-Y., Hsieh C.-L., Leung Y.-M., J. Nat. Prod., 72, 830-834 (2009). 
6) Le Verge R., Le Corre P., Chevanne F., Döe De Maindreville M., Royer D., Levy J., J. Chromatogr., 574, 283-292 (1992).

7) Le Corre P., Dollo G., Chevanne F., Le Verge R., Eur. J. Pharm. Sci., 9, 79-84 (1999).

8) Lee S. K., Kim G. H., Kim D. H., Kim D. H., Jahng Y., Jeong T. C., Biol. Pharm. Bull., 30, 1991-1995 (2007).

9) Nakazawa T., Banba K., Hata K., Nihei Y., Hoshikawa A., Ohsawa K., Biol. Pharm. Bull., 29, 1671-1677 (2006).

10) Wang Y., Wang S., Liu Y., Yan L., Dou G., Gao Y., J. Chromatogr. B, 844, 292-300 (2006).

11) Daniel W. A., Syrek M., Haduch A., Eur. Neuropsychopharmacol., 12, $371-377$ (2002).
12) Ghosal A., Yuan Y., Hapangama N., Su A. D. (I.), Alvarez N., Chowdhury S. K., Alton K. B., Patrick J. E., Zbaida S., Biopharm. Drug Dispos., 25, 243-252 (2004).

13) Yu L., Lu S., Lin Y., Zeng S., Biochem. Pharmacol., 73, 1842-1851 (2007).

14) Yuan D., Ma B., Wu C., Yang J., Zhang L., Liu S., Wu L., Kano Y., J. Nat. Prod., 71, 1271-1274 (2008).

15) Tateishi T., Miura M., Suzuki T., Uno T., Br. J. Clin. Pharmacol., 65, 693-700 (2008).

16) Ardakani Y. H., Rouini M.-R., Biopharm. Drug Dispos., 28, 527—534 (2007).

17) Laus G., J. Chem. Soc., Perkin Trans. 2, 1998, 315-317 (1998). 